\title{
OS ESTUDOS DA ENUNCIAÇÃO E A FORMAÇÃO DO PROFESSOR DE LÍNGUAS
}

\author{
Kelly C. Granzotto Werner \\ kcgbr@yahoo.com.br
}

\section{RESUMO}

Este trabalho apresenta algumas reflexões a respeito de como os estudos da enunciação, principalmente da teoria da subjetividade de Émile Benveniste, podem contribuir para a formação de professores de línguas (estrangeiras). Acreditamos que noções de língua/linguagem, subjetividade e sentido podem ajudar a esses profissionais na sua prática pedagógica. O presente estudo justifica-se principalmente pela busca constante de leituras e atitudes que venham a continuar a formação profissional, reforçando a formação reflexiva de professores de línguas. "A primeira condição para que um ser possa assumir um ato comprometido está em ser capaz de agir e refletir." (Freire, 1983:16).

\section{CONSIDERAÇÕES INICIAIS}

Investigar... encontrar... refletir...buscar alternativas para ajudar na melhor formação do professor de língua estrangeira foi o que moveu este estudo. Como docente num curso de formação de professores, inquietações são constantes a esse respeito.

Sabemos que a formação do professor vai além da aprendizagem durante o período de tempo do curso de licenciatura, uma vez que não podemos pensar que o aluno está pronto, soube o que deveria saber para desempenhar a profissão. Na verdade, neste tempo, os professores estão legalmente e institucionalmente habilitados para lecionar. Mas, sempre há a falta em relação ao conhecimento, há a necessidade de aperfeiçoamento, do estudo e da pesquisa constante, e isso não é apenas delegado pela ordem social. Muitos discursos confirmam que a sociedade "exige", está "desse jeito" e, por isso é que o professor (e não só ele) precisa estar sempre se atualizando, continuando a sua formação. No entanto, é necessário reconhecer que o ser humano é incompleto, é um ser sempre ávido de desejos. Então, as vontades do próprio indivíduo e do meio onde se encontra determinam a natureza da formação.

Partindo disso é que surge a questão que vai nortear este trabalho: em que os estudos da enunciação feitos por Benveniste poderiam contribuir para a formação do profissional de Letras, principalmente, na área do ensino de línguas (estrangeiras)? Trabalhando com discurso e enunciação, essa inquietude é constante. Sendo assim, 
pretendo explicitar conceitos e concepções dos estudos da enunciação de Benveniste que venham a contribuir positivamente para o professor de línguas em formação e refletir sobre a implicância disso na prática docente desses futuros professores. Acredito que os estudos da enunciação de Benveniste contribuíram e contribuem significativamente não só para a lingüística moderna, mas também para a formação do professor de línguas com conceitos fundamentais como o de subjetividade (que antes fora marginalizado) e com a revisão da noção de língua/linguagem e sentido. Desse modo, conhecer essas noções que deram uma reviravolta nos estudos lingüísticos, mudando o modo de pensar dos lingüistas, é importante para o professor de línguas, uma vez que podem ajudá-lo a definir uma concepção de língua/linguagem, de sujeito, de sentido e de ensino e aprendizagem para a sua prática pedagógica.

\section{A TEORIA DA ENUNCIAÇÃO DE BENVENISTE E SUAS CONTRIBUIÇÕES PARA OS ESTUDOS LINGÜÍSTICOS}

Os estudos sobre a enunciação, em geral, principalmente, a teoria enunciativa proposta por Benveniste, trazem para o cenário das preocupações lingüísticas, sem desconsiderar as proposições estruturalistas anteriores, o sujeito, personagem tido como secundário pela lingüística saussuriana. Com a noção de subjetividade, outras também emergiram - as noções de sentido e contexto (referente) - que juntas possibilitaram uma nova forma de pensar a língua/linguagem.

\subsection{A NOÇÃO DE LÍNGUA/LINGUAGEM}

A perspectiva de entendimento de língua de Benveniste se diferencia da de Saussure, uma vez que a vê como essencialmente social, concebida no consenso coletivo. Para o teórico da enunciação (1989, p. 63), “(...) somente a língua torna possível a sociedade. A língua constitui o que mantém juntos os homens, o fundamento de todas as relações que por seu turno fundamentam a sociedade." O fundador da lingüística moderna pensava na língua como um código fechado em si mesmo, estruturado por signos. A forma como Benveniste pensa a língua advém do seu entendimento de signo. Considerando sua forma de significação, propõe dois planos de sentido: o semiótico e o semântico. No primeiro, que confere com o pensamento de Saussure, 
está o signo significando no sistema e, no segundo, há a expressão do sentido resultante da relação do signo com o contexto, ou seja, o modo de significar do enunciado (discurso). Para o autor, essa forma de significar é a língua como trabalho social. Assim, Benveniste vê a língua no seio da sociedade e da cultura porque, para ele, o social é da natureza do homem e da língua.

O entendimento de língua, mostrado por Benveniste, também vai refletir na concepção de linguagem que defende. Esta não é entendida como aquela que serve de instrumento de comunicação ao homem. Em seu estudo Da subjetividade na linguagem, Benveniste (1991, p.85) questiona e critica essa noção de linguagem dizendo que "Falar de instrumento, é pôr em oposição o homem e a natureza", mostrando que não se pode mais conceber a linguagem e o indivíduo dessa forma porque "não atingimos nunca o homem separado da linguagem e não o vemos nunca inventando-a". $\mathrm{Na}$ verdade, essa concepção deixa o indivíduo à margem da linguagem. O que propõe então é uma idéia de linguagem que dê ao indivíduo o status de sujeito e assim deve ser porque "é um homem falando que encontramos no mundo, um homem falando com outro homem, e a linguagem ensina a própria definição do homem".

Dessa forma, a linguagem será o lugar onde o indivíduo se constitui como falante e como sujeito. Essa noção está desenvolvida na teoria da enunciação postulada por Benveniste, a qual direciona os estudos sobre a linguagem para uma nova situação.

\subsection{A NOÇÃO DE SUBJETIVIDADE}

Benveniste, em seus estudos sobre a enunciação, não pretendia fazer uma teoria do sujeito, como já é sabido, mas sim se preocupava com a significação. Apesar disso, sua maior contribuição para a lingüística moderna é a questão da subjetividade. Ela veio à tona porque é inevitável sua presença quando se estuda a linguagem e o sentido. Sendo assim, o sujeito é o cerne da sua teoria da enunciação.

Segundo Benveniste (1991, p.288), a subjetividade é entendida como "a capacidade do locutor para se propor como "sujeito". Essa proposição como sujeito tem como condição a linguagem. "É na linguagem e pela linguagem que o homem se constitui como sujeito; porque só a linguagem fundamenta na realidade, na sua realidade que é a do ser, o conceito de ego". Assim sendo, essa propriedade da subjetividade é 
determinada pela pessoa e o seu status lingüístico. Além disso, para o referido autor, a subjetividade é percebida materialmente num enunciado através de algumas formas (dêixis, verbo) que a língua empresta ao indivíduo que quer enunciar; e quando o faz transforma-se em sujeito. Classifica essas marcas lingüísticas, que têm o poder de expressar a subjetividade, os pronomes e o verbo, integrando essas duas classes de palavras na categoria de pessoa, proposta em 1946.

Nesse texto de 1946, Benveniste, ao instaurar a categoria de pessoa, define as pessoas do discurso. Considera eu/tu como as autênticas pessoas em oposição a ele - a não-pessoa. As pessoas eu/tu se caracterizam como categorias de discurso que só ganham plenitude quando assumidas por um falante, na instância discursiva. Essa tomada é sempre única, móvel e reversível, representando a (inter)subjetividade na linguagem. A terceira pessoa (a não-pessoa, ele), ao contrário, é um signo pleno, uma categoria da língua, que tem referência objetiva e seu valor independe da enunciação, declarando, portanto, a objetividade. A oposição entre os participantes do diálogo e os não participantes resulta em duas correlações: personalidade e subjetividade. A correlação de personalidade opõe a pessoalidade, presente em eu/tu, e a não pessoalidade, presente em ele; já a correlação de subjetividade descreve a oposição existente entre o eu (pessoa subjetiva) e o não-eu (pessoa não-subjetiva). Tais correlações se estendem aos pronomes no plural que, nessa teoria, significam mais que pluralização. Então, Benveniste inova ao dizer que os pronomes pessoais no plural não expressam somente plural. É o caso de nós e vós. Somente "eles" - por não ter marca de pessoa - indica verdadeiro plural. Ainda, define o nós como inclusivo (união de um eu, pessoa subjetiva, a um tu/vós, pessoa não subjetiva) e como exclusivo (eu, pessoa + ele(s), não pessoa). Não podem significar plural porque não demonstram a repetição da mesma pessoa. No caso do nós, não há soma de diferentes pessoas e não há repetição de "eus"; no caso do vós, no sentido coletivo ou de cortesia, não há soma de vários "tus". Então, o fato a que chama atenção Benveniste é que os pronomes não devem ser mais considerados, e o são habitualmente, como uma "classe unitária" quando se refere à forma e à função, diferenciando o aspecto formal dos pronomes, pertencente à parte sintática da língua, do funcional, considerado característico da instância do discurso, ou seja, da enunciação. Quer dizer, os pronomes se configuram numa classe da língua que opera no formal, sintático, e no funcional, pragmático. Sendo assim, os pronomes devem ser 
entendidos também como fatos de linguagem, pertencentes à mensagem (fala), às categorias do discurso e não apenas como pertencentes ao código (língua), às categorias da língua, como considerava Saussure. Essa visão dos pronomes, também como categoria de linguagem, é dada pela posição que nela ocupam.

Desse modo, acredita-se que, para encontrar e tentar entender o sujeito e suas representações na teoria enunciativa de Benveniste, é necessário partir da categoria de pessoa. De acordo com Gomes (2004), "A subjetividade é vista como uma propriedade da língua realizável pela categoria de pessoa". Da mesma forma, Santos (2002, p.25), afirma que

\footnotetext{
O fundamento da subjetividade repousa sobre a categoria de pessoa presente no sistema da língua; todavia essa subjetividade depende da inversibilidade do par eu-tu, a qual assegura um fator fundamental na atribuição de sentido à categoria de pessoa - a intersubjetividade.
}

Segundo Benveniste (1989, p.87), "o que caracteriza a enunciação é a acentuação da relação discursiva com o parceiro, seja este real ou imaginário, individual ou coletivo". Isso determina a estrutura do quadro figurativo da enunciação, o do diálogo, que tem obrigatoriamente um eu e um tu. Os dois participantes alternam as funções, caracterizando-se como parceiros e protagonistas na situação de enunciação. Isso, na verdade, vai criar uma relação intersubjetiva entre as pessoas do enunciado.

\section{POSSÍVEIS CONTRIBUIÇÕES DA TEORIA ENUNCIATIVA DE BENVENISTE PARA A FORMAÇÃO DO PROFESSOR DE LÍNGUA}

Freire (1982, p.42) afirma que "Toda prática educativa implica numa concepção dos seres humanos e do mundo". Dessa forma, o professor de língua (estrangeira) também deve ter concepções claras sobre língua/linguagem, sujeito e o próprio processo de ensino-aprendizagerm, uma vez que o modo como são entendidos tais aspectos refletirá na sua prática pedagógica e na educação.

Retomando o pensamento de Benveniste sobre a concepção de língua e linguagem, percebemos que é entendida como o lugar e o fundamento da subjetividade, e esta, por sua vez, é percebida e tem valor numa relação dialógica, intersubjetiva. Os sujeitos, via língua, constroem sentidos interativamente no discurso. 
Assim sendo, considerar tais idéias da teoria enunciativa benvenistiana contribui, com certeza, para a formação do professor de língua e para o momento de ensinoaprendizagem porque este processo também será entendido como social, interativo, intersubjetivo e construído entre um eu (professor) e vários tus (alunos). Quer dizer, o ensinar e o aprender só acontecem quando são construídos socialmente. Não há como separar os dois pólos e pensar que alguém ensina e outros aprendem. Conforme Freire (1982, p.28), "Ninguém educa ninguém" porque cada indivíduo é sujeito de sua educação e isso se caracteriza por um a relação dialógica e interdependente. A partir disso, é necessário considerar o saber do aluno, muitas vezes, empírico com o saber científico que traz o professor, amalgamando-os, a fim de que o processo educativo seja construído pela relação social estabelecida na sala de aula. Isso será possível se o professor valorizar as subjetividades, o diálogo; se tiver um entendimento de que essas subjetividades têm como condição necessária de existência a intersubjetividade, expressada via língua, e que, nessa situação, constroem o sentido de educação mútua.

Portanto, acreditamos que a teoria da enunciação, caracterizada uma teoria da subjetividade na linguagem, pode contribuir significativamente na formação do professor de língua (estrangeira), pois pode ajudar na sua concepção de língua, linguagem, de sujeito, de sentido. Lastimavelmente, a teoria da enunciação, especificamente a teoria subjetiva de Benveniste, não é leitura freqüente nos cursos de graduação em Letras.

\section{ALGUMAS CONSIDERAÇÕES FINAIS}

Este trabalho buscou apontar noções relevantes dos estudos sobre a enunciação, especificamente de Benveniste, para a formação do professor de língua (estrangeira). Julgamos que o entendimento de língua e linguagem, de sujeito e de sentido apresentados só podem contribuir positivamente para o professor e para a sua prática pedagógica. Queremos concluir estas reflexões, com o pensamento do início deste trabalho: buscar o conhecimento, continuar a formação, refletir sobre a profissão. Isso deve ser a constante preocupação do homem, independentemente de sua área de atuação. Refletir sobre a teoria da enunciação benvenistiana na formação do professor e no ensino de língua foi o objetivo deste trabalho. 


\section{BIBLIOGRAFIA}

BENVENISTE, E. Estrutura das relações de pessoa no verbo. In: Problemas de Lingüística Geral I. 3 ed. São Paulo: Pontes, 1991.

.O aparelho formal da enunciação. In: Problemas de Lingüística Geral II. 3 ed. São Paulo: Pontes, 1989.

.A natureza dos pronomes. In: Problemas de Lingüística Geral I. 3 ed. São Paulo: Pontes, 1991.

.Da subjetividade na linguagem. In: Problemas de Lingüística Geral I. 3 ed. São Paulo: Pontes, 1991.

FREIRE, P. Educação e mudança. 6 ed. Rio de Janeiro: Paz e Terra, 1983.

Ação cultural para a liberdade e outros escritos. 6 ed. Rio de Janeiro: Paz e Terra, 1982.

SANTOS, Elisângela Rosa. Sintaxe e significação: um estudo enunciativo das orações relativas no português. URFRGS, 2002. Dissertação (Mestrado em Letras)- Universidade Federal do Rio Grande do Sul, 2002. 